\title{
Vitamin D and health-related quality of life in a community sample of older Canadians
}

\author{
Y. S. Chao $\cdot$ J. P. Ekwaru $\cdot$ A. Ohinmaa • \\ G. Griener • P. J. Veugelers
}

Accepted: 11 April 2014/Published online: 24 April 2014

(C) The Author(s) 2014. This article is published with open access at Springerlink.com

\begin{abstract}
Purpose To assess how vitamin D status is associated with health-related quality of life (HRQOL) among older residents of Canada.

Design We analysed baseline data of 1,493 Canadians aged 50 years and over in Alberta on HRQOL (EQ-5D-5L) and serum 25 -hydroxyvitamin $\mathrm{D}(25(\mathrm{OH}) \mathrm{D})$ as a measure of vitamin D status. We applied multivariable regression methods to examine the association between vitamin D status and each of the five dimensions and the summary index of the EQ-5D-5L.

Results Participants with higher serum 25(OH)D levels were significantly less likely to report problems with mobility, usual activities, and depression and anxiety. Specifically, age- and gender-adjusted odds ratios for reporting problems with mobility, usual activities, and depression and anxiety were 0.58 (95\% confidence interval $0.44-0.78$ ), $0.67(0.50-0.89)$, and $0.67(0.51-0.88)$ per $100 \mathrm{nmol} / \mathrm{L}$ increase in $25(\mathrm{OH}) \mathrm{D}$, respectively. No significant associations were observed for problems with self-care and with pain and discomfort. HRQOL scores combining the responses of each of the five dimensions increased significantly with increasing serum $25(\mathrm{OH}) \mathrm{D}$ levels.

Conclusions This is the first study to reveal the importance of vitamin D for the five dimensions of HRQOL in a community-based sample. The observed associations of vitamin D and HRQOL call for intervention studies to strengthen the evidence of the potential benefits of vitamin D supplementation for HRQOL among older adults.
\end{abstract}

Y. S. Chao · J. P. Ekwaru - A. Ohinmaa - G. Griener ·

P. J. Veugelers $(\square)$

School of Public Health, University of Alberta, 3-50 University

Terrace, 8303 - 112 Street, Edmonton, AB T6G 2T4, Canada

e-mail: paul.veugelers@ualberta.ca
Keywords Health-related quality of life · Vitamin D . Public health · Disease prevention

\section{Introduction}

Vitamin D has been shown to affect bone health and various chronic diseases [1]. To mediate on the burden of some of these conditions, the Institute of Medicine and Health Canada recommend vitamin D supplementation of $600 \mathrm{IU}$ per day for adults and $800 \mathrm{IU}$ per day for those above the age of 70 years $[2,3]$. Supplementation may be particularly important to residents of northern geographies, such as Canada, as subcutaneous creation of vitamin D by sun exposure is limited [4]. In Canada, vitamin D deficiency and insufficiency continue to be prevalent despite the recommendations for Vitamin D supplementation [5]. Specifically, the Canadian Health Measures Survey had shown that 4.1 and $10.6 \%$ (95\% confidence interval 2.9-5.8 and 8.2-13.6\%, respectively) of Canadians aged 6-79 years had serum 25 -hydroxyvitamin $\mathrm{D}<27.5$ and $37.5 \mathrm{nmol} / \mathrm{L}$, respectively [5]. We recently showed that the rates of deficiency and insufficiency were 3 and $8 \%$, respectively, in a sample of working age Canadians [6].

For older populations, several vitamin D supplementation studies have suggested, though not consistently, less functional limitation [7], prevention of falls [8-10], reductions in fractures [11-13], and mental health benefits $[14,15]$. A meta-analysis by Bischoff-Ferrari et al. [9] concluded that in order to achieve a reduction in falls a supplementation dose of 700-1,000 IU per day is needed which is close to what is currently recommended by the Institute of Medicine. The above studies suggest a relationship of vitamin D and objectively measured health conditions. Health-related quality of life (HRQOL) aims to 
quantify the subjective experiences of the consequences of these health conditions. The importance of vitamin D for HRQOL has been less studied. Huang et al. [16] attributed improvements in quality of life along with improvements in pain and sleep to vitamin $\mathrm{D}$ supplementation in a case series of individuals with chronic pain. However, to the best of our knowledge, no earlier studies have examined the association of vitamin $D$ with the full spectrum of HRQOL in healthy populations. We believe that this is particularly important as the Institute of Medicine recommendations are issued to the general public. We also believe these are particular important to Canadians given the relatively high latitude and consequent reliance on vitamin $\mathrm{D}$ from diet and supplements. In the present study, we assess the association of vitamin D status and HRQOL among older residents of Canada.

\section{Methods}

This is a cross-sectional study based on information gathered at baseline visits from volunteer participants before starting a wellness programme by the Pure North S'Energy Foundation (PN). PN, a charitable, not-forprofit organization, provides a lifestyle counselling programme as described in more detail elsewhere [6, 17, 18]. As of August of 2012, PN started the recruitment of older residents of the city of Calgary, Alberta, Canada. PN advertised their programme for seniors through local newsletters and through the distribution of flyers in senior homes and community centres. PN would organize weekly information meetings after which attendees could elect to sign up to enrol the programme. The present study pertains to baseline observations of older residents recruited between August 2012 and April 2013.

At their baseline visit, participants completed a survey had their body height and weight measured and their blood drawn for the assessment of serum 25-hydroxyvitamin D $(25(\mathrm{OH}) \mathrm{D})$. The survey included the five-level EQ-5D (EQ-5D-5L) to measure health-related quality of life (HRQOL) [19]. The EQ-5D consists of a five-dimensional descriptive system asking whether participants have (1) no problems; (2) slight problems; (3) moderate problems; (4) severe problems; or (5) extreme conditions or are unable to perform or extreme conditions are fully constrained or restricted, with each of the following: (1) mobility; (2) selfcare; (3) usual activities; (4) pain or discomfort; and (5) anxiety or depression [19]. HRQOL scores are based on responses to each of the five dimensions and were derived from the USA value sets [20]. The EQ-5D is an established and validated instrument [19] with the major advantages of being short and easy to complete [21].
The survey further included questions on age, gender, and income. Individuals and couples with an annual income of $<\$ 25,000$ and of $<\$ 41,000$, respectively [22], were considered as low income. Body mass index (BMI) was calculated on the basis of the measured heights and weights (weights in kilograms divided by the square of height in metres). Individuals with a BMI of 25 or more are considered overweight, and those with a BMI of 30 or more are considered obese [23].

Serum $25(\mathrm{OH}) \mathrm{D}$ is the established proxy for vitamin D status. Some have suggested that individuals with serum 25(OH)D levels below $25 \mathrm{nmol} / \mathrm{L}$ should be considered vitamin $\mathrm{D}$ deficiency and those with serum $25(\mathrm{OH}) \mathrm{D}$ levels of 25 or more and $<50 \mathrm{nmol} / \mathrm{L}$ be considered vitamin $\mathrm{D}$ insufficiency. As recent studies have suggested extraskeletal benefits, such as reduction in colorectal cancer and cardiovascular disease risk, for individuals with serum levels of $75 \mathrm{nmol} / \mathrm{L}$ or more $[1,24,25]$, and given the large number of observations with serum levels above $75 \mathrm{nmol} / \mathrm{L}$, we further categorized serum levels into $\geq 75$ and $<100$, $\geq 100$ and $<125$, and $\geq 125 \mathrm{nmol} / \mathrm{L}$.

As descriptive statistics, we included the prevalence of problems in the five HRQOL dimensions by vitamin D category and by age, gender, income, and bodyweight status. We tested for differences in the prevalence of HRQOL problems across vitamin D status categories by the use of univariate logistic regression. We applied univariate and multivariable logistic regression to quantify the association of vitamin D status with problems in each of the five HRQOL domains whereby we had dichotomized the latter into 'having no problems' (level 1) and 'having problems' (levels 2-5 combined). As HRQOL scores were skewed to the left, with values ranging from 0.129 to 1.0 , we log-transformed inverse of the HRQOL scores, i.e. $\log _{10}(1.0001-$ HRQOL). These ' $\log$ of inverse HRQOL scores' increase with poorer HRQOL and constitute the dependent variables in univariate and multivariable linear regression analyses to quantify the significance of vitamin D status for overall HRQOL. $p$ values $<0.05$ were considered statistically significant.

PN anonymized their data prior to forwarding it to the University of Alberta for statistical analysis. The analysis was conducted using STATA version 12 (College Station, Texas). The Human Research Ethics Board of the University of Alberta approved the data access and analysis for this study.

\section{Results}

The mean serum 25(OH)D level among the 1,493 participants was $92.44 \mathrm{nmol} / \mathrm{L}$ and ranged from 12 to $319 \mathrm{nmol} / \mathrm{L}$. Thirteen participants $(0.9 \%)$ had serum $25(\mathrm{OH}) \mathrm{D}$ levels of 
$<25 \mathrm{nmol} / \mathrm{L}$, and $116(7.8 \%)$ had $25(\mathrm{OH}) \mathrm{D}$ levels between 25 and $50 \mathrm{nmol} / \mathrm{L}$ (Table 1). Table 1 shows prevalence of problems by vitamin $\mathrm{D}$ status for each of the five EQ-5D dimensions and for any of these five problems. Though there are some slight fluctuations, the percentages of participants having problems in each of the five EQ-5D dimensions generally declined with higher categories of serum $25(\mathrm{OH})$ D. Table 1 also shows associations between age, gender, income, and body weight and HRQOL. These associations are mostly substantial in magnitude and statistically significant.

Table 2 shows the unadjusted and adjusted associations between $25(\mathrm{OH}) \mathrm{D}$ levels and having problems in each of the five EQ-5D dimensions. In the unadjusted analysis, each $100 \mathrm{nmol} / \mathrm{L}$ increase in 25(OH)D was significantly associated with a reduction in the odds of having problems with mobility (39\%), usual activities (30\%), pain and discomfort $(26 \%)$, and any problem $(37 \%)$. These associations remained statistically significant after adjusting for age and gender. Further, adjustment for income and body weight reduced the magnitude of the associations and only the association with anxiety or depression and any problem remained statistically significant.

Figure 1 shows the mean values of HRQOL scores measured with EQ-5D-5L by vitamin D status. The mean HRQOL scores increased with increasing levels of vitamin D. Table 3 shows unadjusted and adjusted associations between the log of inverse HRQOL score and vitamin D levels, gender, age, weight status, and income. After adjusting for gender, age, weight status, and income, each $100 \mathrm{nmol} / \mathrm{L}$ increase in vitamin D level was associated with a 0.15 (95\% CI 0.01, 0.29 ) statistically significant reduction in the log of inverse HRQOL score, which corresponds to a statistically significant increase in HRQOL score. A reduction in 0.15 in the log of inverse HRQOL score ( $1-\mathrm{HRQOL})$ is equivalent to an increase in HRQOL score of about $29\left(\frac{1-\mathrm{HRQOL}_{0}}{\mathrm{HRQOL}_{0}}\right) \%$ at any given initial HRQOL score $\mathrm{HRQOL}_{0}$. Therefore, at a HRQOL score of 0.5 a $100 \mathrm{nmol} / \mathrm{L}$ increase in $25(\mathrm{OH}) \mathrm{D}$ results in a $29 \%$ increase in HRQOL score. The percentage increase is higher than $29 \%$ if the initial HRQOL score is below less 0.5 and $<29 \%$ if the initial HRQOL score is above 0.5 .

Table 1 Prevalence of problems in the EQ-5D dimensions among 1,493 study participants

\begin{tabular}{|c|c|c|c|c|c|c|c|c|c|c|c|c|c|}
\hline \multirow[t]{2}{*}{ Variable } & \multirow[t]{2}{*}{$\mathrm{N}$} & \multicolumn{2}{|c|}{$\begin{array}{l}\text { Problems with } \\
\text { mobility }\end{array}$} & \multicolumn{2}{|c|}{$\begin{array}{l}\text { Problems with } \\
\text { self-care }\end{array}$} & \multicolumn{2}{|c|}{$\begin{array}{l}\text { Problems with } \\
\text { usual activities }\end{array}$} & \multicolumn{2}{|c|}{$\begin{array}{l}\text { Problems with } \\
\text { pain and } \\
\text { discomfort }\end{array}$} & \multicolumn{2}{|c|}{$\begin{array}{l}\text { Problems with } \\
\text { depression and } \\
\text { anxiety }\end{array}$} & \multicolumn{2}{|c|}{ Any problem } \\
\hline & & $\%$ & $p$ value & $\%$ & $p$ value & $\%$ & $p$ value & $\%$ & $p$ value & $\%$ & $p$ value & $\%$ & $p$ value \\
\hline \multicolumn{14}{|l|}{$25(\mathrm{OH}) \mathrm{D}$ level } \\
\hline$<25 \mathrm{nmol} / \mathrm{L}$ & 13 & 53.8 & 0.65 & 7.7 & 0.84 & 38.5 & 1.00 & 76.9 & 0.58 & 61.5 & 0.64 & 92.3 & 0.88 \\
\hline$\geq 25,<50 \mathrm{nmol} / \mathrm{L}$ & 116 & 47.4 & 0.98 & 12.1 & 0.03 & 51.7 & $<.01$ & 80.2 & 0.48 & 62.1 & 0.18 & 91.4 & 0.89 \\
\hline$\geq 50,<75 \mathrm{nmol} / \mathrm{L}$ & 385 & 47.5 & ref. & 6.2 & ref. & 38.4 & ref. & 83.1 & ref. & 55.1 & ref. & 90.9 & ref. \\
\hline$\geq 75,<100 \mathrm{nmol} / \mathrm{L}$ & 461 & 39.0 & 0.01 & 6.3 & 0.97 & 38.4 & 0.99 & 79.8 & 0.23 & 54.4 & 0.86 & 89.2 & 0.42 \\
\hline$\geq 100,<125 \mathrm{nmol} / \mathrm{L}$ & 290 & 35.2 & $<.01$ & 5.5 & 0.71 & 33.8 & 0.22 & 79.7 & 0.26 & 53.4 & 0.68 & 85.9 & 0.04 \\
\hline$>125 \mathrm{nmol} / \mathrm{L}$ & 228 & 34.2 & $<.01$ & 7.5 & 0.56 & 35.1 & 0.41 & 78.9 & 0.21 & 49.1 & 0.15 & 86.0 & 0.06 \\
\hline \multicolumn{14}{|l|}{ Gender } \\
\hline Female & 971 & 40.8 & 0.78 & 6.7 & 0.88 & 39.5 & 0.10 & 82.9 & $<.01$ & 59.5 & $<.01$ & 90.6 & $<.01$ \\
\hline Male & 522 & 40.0 & ref. & 6.9 & ref. & 35.2 & ref. & 76.1 & ref. & 44.4 & ref. & 85.1 & ref. \\
\hline \multicolumn{14}{|l|}{ Age (years) } \\
\hline $50-59$ & 356 & 36.2 & $<.01$ & 5.9 & $<.01$ & 40.4 & 0.01 & 82.3 & 0.70 & 65.7 & $<.01$ & 91.9 & 0.38 \\
\hline $60-69$ & 687 & 38.9 & $<.01$ & 5.1 & $<.01$ & 34.2 & $<.01$ & 80.5 & 0.99 & 53.9 & 0.16 & 88.2 & 0.93 \\
\hline 70-79 & 363 & 43.0 & $<.01$ & 8.0 & $<.01$ & 38.8 & $<.01$ & 78.8 & 0.72 & 45.7 & 0.97 & 86.5 & 0.60 \\
\hline $80+$ & 87 & 60.9 & ref. & 18.4 & ref. & 55.2 & ref. & 80.5 & ref. & 46.0 & ref. & 88.5 & ref. \\
\hline \multicolumn{14}{|l|}{ Income } \\
\hline Other & 853 & 33.5 & ref. & 4.1 & ref. & 30.4 & ref. & 77.7 & ref. & 51.2 & ref. & 86.3 & ref. \\
\hline Low income & 640 & 49.8 & $<.01$ & 10.3 & $<.01$ & 48.3 & $<.01$ & 84.2 & $<.01$ & 58.3 & $<.01$ & 91.9 & $<.01$ \\
\hline \multicolumn{14}{|l|}{ Weight status } \\
\hline $\begin{array}{l}\text { Underweight or } \\
\text { normal weight }\end{array}$ & 479 & 26.9 & ref. & 5.8 & ref. & 29.6 & ref. & 76.0 & ref. & 54.5 & ref. & 86.0 & ref. \\
\hline Overweight & 593 & 40.5 & $<.01$ & 5.2 & 0.69 & 36.9 & 0.01 & 80.8 & 0.05 & 52.6 & 0.54 & 89.4 & 0.08 \\
\hline Obesity & 421 & 56.1 & $<.01$ & 10.0 & 0.01 & 49.2 & $<.01$ & 85.3 & $<.01$ & 56.3 & 0.59 & 90.7 & 0.03 \\
\hline
\end{tabular}

Ref.: reference category, 25(OH)D: serum 25-hydroxyvitamin D level, $p$ value: Compared with the reference category 
Table 2 Changes in the odds of each EQ-5D dimension problems per $100 \mathrm{nmol}$ increase in 25(OH)D/L among 1,493 study participants

\begin{tabular}{|c|c|c|c|c|c|c|c|c|c|}
\hline \multirow[t]{2}{*}{ Problem } & \multicolumn{3}{|l|}{ Unadjusted } & \multicolumn{3}{|c|}{ Adjusted for age and gender } & \multicolumn{3}{|c|}{$\begin{array}{l}\text { Adjusted for age, gender, } \\
\text { income, and weight status }\end{array}$} \\
\hline & Odds ratio & $95 \% \mathrm{CI}$ & $p$ value & Odds ratio & $95 \% \mathrm{CI}$ & $p$ value & Odds ratio & $95 \% \mathrm{CI}$ & $p$ value \\
\hline Problems with mobility & 0.61 & $0.46-0.80$ & $<.01$ & 0.58 & $0.44-0.78$ & $<.01$ & 0.82 & $0.61-1.10$ & 0.18 \\
\hline Problems with self-care & 0.89 & $0.52-1.53$ & 0.68 & 0.88 & $0.51-1.52$ & 0.65 & 1.11 & $0.65-1.91$ & 0.70 \\
\hline Problems with usual activities & 0.70 & $0.53-0.92$ & 0.01 & 0.67 & $0.50-0.89$ & $<.01$ & 0.87 & $0.65-1.18$ & 0.37 \\
\hline Problems with pain and discomfort & 0.85 & $0.61-1.17$ & 0.32 & 0.79 & $0.57-1.10$ & 0.16 & 0.95 & $0.67-1.34$ & 0.77 \\
\hline Problems with depression and anxiety & 0.74 & $0.57-0.97$ & 0.03 & 0.67 & $0.51-0.88$ & $<.01$ & 0.71 & $0.53-0.94$ & 0.02 \\
\hline Any problem & 0.63 & $0.43-0.91$ & 0.02 & 0.58 & $0.39-0.84$ & $<.01$ & 0.66 & $0.44-0.98$ & 0.04 \\
\hline
\end{tabular}

CI confidence interval, $25(\mathrm{OH}) \mathrm{D}$ serum 25-hydroxyvitamin D level

Fig. 1 Mean HRQOL score by vitamin D category among 1,493 study participants. $25(\mathrm{OH}) \mathrm{D}$ serum 25-hydroxyvitamin D level, $H R Q O L$ health-related quality of life.

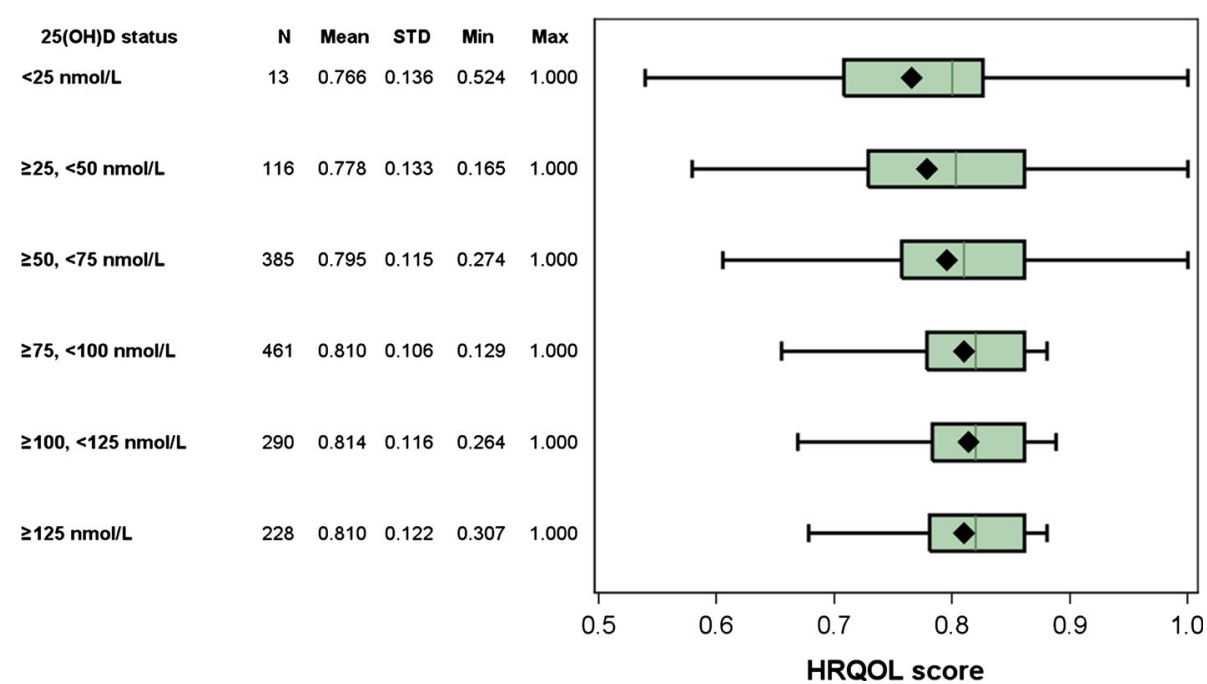

\section{Discussion}

This is the first study to report on the associations of vitamin D with each of the five dimensions of quality of life. The study revealed significant associations of vitamin D with problems with mobility, usual activities, and depression and anxiety. It further revealed that an increase of $100 \mathrm{nmol} / \mathrm{L}$ of serum $25(\mathrm{OH}) \mathrm{D}$ is associated with an average increase of $29 \%$ in HRQOL.

The average serum 25(OH)D level of participants was $92.44 \mathrm{nmol} / \mathrm{L}$ which is substantially higher than the average among Canadians aged 6 to $79(67.7 \mathrm{nmol} / \mathrm{L})$ and among Canadians $60-79$ years of age $(72.0 \mathrm{nmol} / \mathrm{L})$ [5]. Self-selection of health aware individuals interested to participate in the wellness programme may have contributed to this. Health aware individuals may eat healthier and comply better with the existing vitamin D supplementation recommendations. This self-selection may particularly apply to individuals with pain and discomfort. We observed that approximately $80 \%$ of participants reported problems with pain and discomfort. This percentage seems higher than those of a population-based survey using EQ$5 \mathrm{D}-3 \mathrm{~L}$ conducted in 2010 in the same province where $57 \%$ of participants between the ages of 45 and 64 years and $66 \%$ of participants 65 years of age and older reported problems with pain and discomfort [26]. Subjects experiencing pain and discomfort may be particularly motivated to participant in the programme.

Gender and age are established determinants of vitamin D status [6, 17] and of quality of life [20]. It is, therefore, essential to adjust for the confounding influence of gender and age as we did in this study. We observed that vitamin $\mathrm{D}$ was associated with three of the five EQ-5D dimensions: mobility, usual activities, and depression or anxiety. The absence of a statistical significant association with self-care may stem from the very low prevalence of reported problems with self-care in this population. Bias by indication [27], whereby individuals with symptoms, pain, and illness are more likely to comply with recommendations, may have led to an underestimation of the strength of the association with each of the five dimensions. However, this may be particularly true for problems with 'pain and 
Table 3 Effect of serum 25(OH)D levels, gender, age, weight status, and income on the log-transformed inverse of health-related quality of life score (i.e. $\log _{10}[1.0001-$ HRQOL]) among 1,493 study participants

\begin{tabular}{|c|c|c|c|c|c|c|}
\hline \multirow[t]{2}{*}{ Variable } & \multicolumn{2}{|l|}{ Unadjusted } & \multicolumn{2}{|c|}{ Adjusted for age and gender } & \multicolumn{2}{|c|}{$\begin{array}{l}\text { Adjusted for age, gender, income, and } \\
\text { weight status }\end{array}$} \\
\hline & $\beta(95 \% \mathrm{CI})$ & $p$ value & $\beta(95 \% \mathrm{CI})$ & $p$ value & $\beta(95 \% \mathrm{CI})$ & $p$ value \\
\hline Serum 25(OH)D (100 nmol/L) & $-0.19(-0.32,-0.05)$ & 0.009 & $-0.22(-0.36,-0.08)$ & 0.002 & $-0.15(-0.29,-0.01)$ & 0.042 \\
\hline \multicolumn{7}{|l|}{ Gender } \\
\hline Female & ref. & & ref. & & ref. & \\
\hline Male & $-0.20(-0.31,-0.09)$ & $<.001$ & $-0.22(-0.33,-0.10)$ & $<.001$ & $-0.22(-0.33,-0.10)$ & $<.001$ \\
\hline \multicolumn{7}{|l|}{ Age(years) } \\
\hline $50-59$ & ref. & & ref. & & ref. & \\
\hline $60-69$ & $-0.14(-0.27,0.00)$ & 0.050 & $-0.11(-0.25,0.02)$ & 0.095 & $-0.15(-0.28,-0.01)$ & 0.034 \\
\hline $70-79$ & $-0.18(-0.33,-0.02)$ & 0.025 & $-0.16(-0.32,-0.01)$ & 0.037 & $-0.22(-0.38,-0.07)$ & 0.005 \\
\hline $80+$ & $-0.07(-0.32,0.18)$ & 0.587 & $-0.04(-0.29,0.20)$ & 0.732 & $-0.12(-0.37,0.12)$ & 0.330 \\
\hline \multicolumn{7}{|l|}{ Weight status } \\
\hline Underweight or normal weight & ref. & & & & ref. & \\
\hline Overweight & $0.12(-0.01,0.24)$ & 0.073 & & & $0.16(0.03,0.28)$ & 0.018 \\
\hline Obesity & $0.21(0.07,0.35)$ & 0.003 & & & $0.21(0.06,0.35)$ & 0.005 \\
\hline \multicolumn{7}{|l|}{ Income } \\
\hline Low income & $0.24(0.14,0.35)$ & $<.001$ & & & $0.23(0.12,0.34)$ & $<.001$ \\
\hline Other & ref. & & & & ref. & \\
\hline
\end{tabular}

In the above analyses, interaction terms of age and serum $25(\mathrm{OH}) \mathrm{D}$ were not associated with health-related quality of life in a statistical significantly manner

$\beta$ coefficient, $C I$ confidence interva, 25(OH)D serum 25-hydroxyvitamin D leve, Ref. reference category, $H R Q O L$ health-related quality of life

discomfort' and explain why no association for this dimension was observed.

Vitamin D has been shown to lead to better muscle strength [28], and, both in observational studies and clinical trials, vitamin D supplementation has been shown to benefit mobility and functional status in terms of prevention of falls [9] and improvement of physical function [29]. Consistent with our observations that individuals with a better vitamin $\mathrm{D}$ status reported less problems with mobility and usual activities, these findings $[9,29]$ seem to suggest less frailty among individuals with a good vitamin D status, though a recent meta-analysis reported that vitamin D supplementation among unselected communitydwelling individuals does not change risk for skeletal or non-skeletal outcomes by more than $15 \%$ [30].

Vitamin D has also been shown to be associated with less depression [14] which seems consistent with our observation that higher vitamin D serum levels are associated with less problems with depression and anxiety. Though the associations with several outcomes are probable, more research is needed for more convincing evidence [31], which may particularly apply to mental health outcomes.

The Institute of Medicine recommendations are issued to the general public, but no earlier study had reported on the association between vitamin D and quality of life in a general population. Though we conducted this in a community sample, caution is warranted when it comes the generalizing our findings as this sample may be selfselected towards a health aware subpopulation with a relatively high prevalence of problems with pain and discomfort. Despite the large sample size, a second study limitation relates to the small number of participants that reported problems with self-care, which hampered some of the analyses. Further, although we did adjust for the confounding effect of age, sex, income, and body weight status, we acknowledge that other factors may have confounded the observed association of 25(OH)D and HRQOL. Further, limitations relate to the cross-sectional design and the existence of reverse causation whereby, for example, individuals with limited mobility due to chronic diseases have less opportunity to get outdoors. A final limitation relates to the use of self-reported information that is prone to error, though the EQ-5D is an established and validated instrument [19] whereby the reporting error is expected to be limited given that it is short and easy to complete [21].

Acknowledgments The authors wish to thank the Pure North S'Energy Foundation for allowing their data to be analysed for the purpose of this article. They specifically wish to thank the Peter Tran and Ken Fyle for management and validation of the Foundation's data. PJV holds a Canada Research Chair in Population Health, an Alberta Research Chair in Nutrition and Disease Prevention, and an 
Alberta Innovates Health Scholarship. The funding for the Canada Research Chair is provided through the Canadian Institutes for Health Research to the University of Alberta. The Alberta Research Chair is awarded by the School of Public Health at the University of Alberta through a thematic research contract with the Pure North S'Energy Foundation. The Health Scholarship is funded by the Alberta provincial government through Alberta Innovates Health Solutions.

\section{Conflict of interest None.}

Open Access This article is distributed under the terms of the Creative Commons Attribution License which permits any use, distribution, and reproduction in any medium, provided the original author(s) and the source are credited.

\section{References}

1. Holick, M. F. (2007). Vitamin D deficiency. The New England Journal of Medicine, 357(3), 266-281.

2. Committee to Review Dietary Reference Intakes for Vitamin D and Calcium Institute of Medicine, (2011). Dietary reference intakes for calcium and vitamin D. Washington, D.C.: The National Academies Press.

3. Health Canada (2012) Vitamin D and calcium: Updated dietary reference intakes. Health Canada. http://www.hc-sc.gc.ca/fn-an/ nutrition/vitamin/vita-d-eng.php. Accessed October 20, 2013.

4. Prentice, A. (2008). Vitamin D deficiency: A global perspective. Nutrition Reviews, 66(10 Suppl 2), S153-S164. doi:10.1111/j. 1753-4887.2008.00100.x.

5. Langlois, K., Greene-Finestone, L., Little, J., Hidiroglou, N., \& Whiting, S. (2010). Vitamin D status of Canadians as measured in the 2007 to 2009 Canadian Health Measures Survey. Health Report, 21(1), 47-55.

6. Chao, Y. S., Brunel, L., Faris, P., \& Veugelers, P. J. (2013). Vitamin D status of Canadians employed in northern latitudes. Occupational Medicine (Oxford, England), 63(7), 485-493. doi:10.1093/occmed/kqt106.

7. Sohl, E., van Schoor, N. M., de Jongh, R. T., Visser, M., Deeg, D. J., \& Lips, P. (2013). Vitamin D status is associated with functional limitations and functional decline in older individuals. The Journal of Clinical Endocrinology and Metabolism, 98(9), E1483-E1490. doi:10.1210/jc.2013-1698.

8. Murad, M. H., Elamin, K. B., Abu Elnour, N. O., Elamin, M. B., Alkatib, A. A., Fatourechi, M. M., et al. (2011). Clinical review: The effect of vitamin D on falls: A systematic review and metaanalysis. The Journal of Clinical Endocrinology and Metabolism, 96(10), 2997-3006. doi:10.1210/jc.2011-1193.

9. Bischoff-Ferrari, H. A., Dawson-Hughes, B., Staehelin, H. B., Orav, J. E., Stuck, A. E., Theiler, R., et al. (2009). Fall prevention with supplemental and active forms of vitamin D: A meta-analysis of randomised controlled trials. BMJ, 339, b3692. doi:10. 1136/bmj.b3692.

10. Janssen, H. C., Samson, M. M., \& Verhaar, H. J. (2002). Vitamin $\mathrm{D}$ deficiency, muscle function, and falls in elderly people. The American Journal of Clinical Nutrition, 75(4), 611-615.

11. Bischoff-Ferrari, H. A., Willett, W. C., Orav, E. J., Lips, P., Meunier, P. J., Lyons, R. A., et al. (2012). A Pooled analysis of vitamin D dose requirements for fracture prevention. New England Journal of Medicine, 367(1), 40-49. doi:10.1056/NEJMoa1109617.

12. Sahota, O. (2010). Reducing the risk of fractures with calcium and vitamin D. BMJ, 340, b5492. doi:10.1136/bmj.b5492.

13. Lips, P., Wiersinga, A., van Ginkel, F. C., Jongen, M. J., Netelenbos, J. C., Hackeng, W. H., et al. (1988). The effect of vitamin $\mathrm{D}$ supplementation on vitamin D status and parathyroid function in elderly subjects. The Journal of Clinical Endocrinology and Metabolism, 67(4), 644-650.

14. Anglin, R. E., Samaan, Z., Walter, S. D., \& McDonald, S. D. (2013). Vitamin D deficiency and depression in adults: systematic review and meta-analysis. The British journal of psychiatry., 202, 100-107. doi:10.1192/bjp.bp.111.106666.

15. Ju, S. Y., Lee, Y. J., \& Jeong, S. N. (2013). Serum 25-hydroxyvitamin D levels and the risk of depression: a systematic review and meta-analysis. The Journal of Nutrition, Health \& Aging, 17(5), 447-455. doi:10.1007/s12603-012-0418-0.

16. Huang, W., Shah, S., Long, Q., Crankshaw, A. K., \& Tangpricha, V. (2013). Improvement of pain, sleep, and quality of life in chronic pain patients with vitamin $\mathrm{D}$ supplementation. The Clinical Journal of Pain, 29(4), 341-347. doi:10.1097/AJP. 0b013e318255655d.

17. Chao, Y. S., Brunel, L., Faris, P., \& Veugelers, P. J. (2013). The importance of dose, frequency and duration of vitamin d supplementation for plasma 25-hydroxyvitamin d. Nutrients, 5(10), 4067-4078. doi:10.3390/nu5104067.

18. Heaney, R. P., French, C. B., Nguyen, S., Ferreira, M., Baggerly, L. L., Brunel, L., et al. (2013). A novel approach localizes the association of vitamin D status with insulin resistance to one region of the 25-hydroxyvitamin D continuum. Advance Nutrition, 4(3), 303-310. doi:10.3945/an.113.003731.

19. Oemar M, Janssen B (2013) EQ-5D-5L User guide basic information on how to use the EQ-5D-5L instrument. http://www. euroqol.org/fileadmin/user_upload/Documenten/PDF/Folders_ Flyers/UserGuide_EQ-5D-5L_v2.0_October_2013.pdf. Accessed March 15, 2014.

20. Herdman, M., Gudex, C., Lloyd, A., Janssen, M., Kind, P., Parkin, D., et al. (2011). Development and preliminary testing of the new five-level version of EQ-5D (EQ-5D-5L). Quality of Life Research, 20(10), 1727-1736. doi:10.1007/s11136-011-9903-x.

21. Tidermark, J., Zethraeus, N., Svensson, O., Törnkvist, H., \& Ponzer, S. (2002). Femoral neck fractures in the elderly: Functional outcome and quality of life according to EuroQol. Quality of Life Research, 11(5), 473-481. doi:10.1023/a: 1015632114068.

22. Harris M (2013) Digital divide persists in Canada, both in access and Internet fluency. Financial Post, March 21, 2013, p Tech Desk.

23. World Health Organization (2013) Obesity and overweight. World Health Organization. http://www.who.int/mediacentre/ factsheets/fs311/en/index.html. Accessed October 1, 2013.

24. Vieth, R., Bischoff-Ferrari, H., Boucher, B. J., Dawson-Hughes, B., Garland, C. F., Heaney, R. P., et al. (2007). The urgent need to recommend an intake of vitamin $\mathrm{D}$ that is effective. The American Journal of Clinical Nutrition, 85(3), 649-650.

25. Health Quality Council of Alberta (2013). Alberta Provincial Norms for EQ-5D-3L. http://www.hqca.ca/assets/files/Alberta\% 20Provincial\%20Norms\%20for\%20EQ-5D\%203L(1).pdf. Accessed March 15, 2014.

26. Bischoff-Ferrari, H. A., Giovannucci, E., Willett, W. C., Dietrich, T., \& Dawson-Hughes, B. (2006). Estimation of optimal serum concentrations of 25-hydroxyvitamin D for multiple health outcomes. The American Journal of Clinical Nutrition, 84(1), 18-28.

27. Signorello, L. B., McLaughlin, J. K., Lipworth, L., Friis, S., Sorensen, H. T., \& Blot, W. J. (2002). Confounding by indication in epidemiologic studies of commonly used analgesics. American Journal of Therapeutics, 9(3), 199-205.

28. Ceglia, L. (2011). Simpson RU (2011) Vitamin D and skeletal muscle function. In D. Feldman, J. W. Pike, \& J. S. Adams (Eds.), Vitamin D. Amsterdam, The Netherlands: Elsevier Science.

29. Bunout, D., Barrera, G., Leiva, L., Gattas, V., de la Maza, M. P., Avendano, M., et al. (2006). Effects of vitamin D supplementation and exercise training on physical performance in Chilean 
vitamin D deficient elderly subjects. Experimental Gerontology, 41(8), 746-752.

30. Bolland, M. J., Grey, A., Gamble, G. D., \& Reid, I. R. (2014).

The effect of vitamin D supplementation on skeletal, vascular, or cancer outcomes: A trial sequential meta-analysis. The lancet Diabetes \& Endocrinology, 2(4), 307-320. doi:10.1016/S22138587(13)70212-2.
31. Theodoratou, E., Tzoulaki, I., Zgaga, L., \& Ioannidis, J. P. A. (2014). Vitamin D and multiple health outcomes: Umbrella review of systematic reviews and meta-analyses of observational studies and randomised trials. BMJ, 348, g2035. doi:10.1136/bmj. g2035. 